\title{
LA RECONFIGURACIÓN Y CONSOLIDACIÓN DE LA ALCABALA EN EL DERECHO PATRIO CHILENO (1810-1866)
}

\author{
RECONFIGURATION AND CONSOLIDATION OF THE ALCABALA \\ WITHIN NATIONAL CHILEAN LAW (1810-1866)
}

\author{
GaBriel BocKSANG Hola*
}

\begin{abstract}
RESUMEN: La alcabala, un impuesto proveniente del derecho de raíz castellano-medieval y presente en el antiguo Reino de Chile, fue recibido desde la Independencia por las autoridades nacionales como un elemento importante del régimen tributario chileno. El período que se extiende desde 1810 hasta 1866 muestra los esfuerzos para reconfigurarla y consolidarla, otorgándole a la alcabala un tratamiento jurídico coherente y permitiendo hallar soluciones tributarias justas en el nuevo contexto republicano de Chile.
\end{abstract}

Palabras clave: Alcabala, impuesto, Chile, contratos, siglo XIX.

ABSTRACT: The alcabala, a Spanish-rooted tax present in the former Kingdom of Chile, was received since the Independence process by national authorities as an important element of the Chilean fiscal system. The period running from 1810 to 1866 shows the efforts held to reconfigure and consolidate it, granting to the alcabala a coherent legal treatment and allowing the finding of fair tax solutions under Chile's new Republican context.

Key words: Alcabala, tax, Chile, contracts, $19^{\text {th }}$ century.

\section{INTRODUCCIÓN}

Procedente del derecho castellano-medieval, la alcabala fue un elemento típico del paisaje tributario chileno durante el siglo XIX. Sus orígenes eran remotos, al punto de ser calificada por una norma capital como "un derecho tan antiguo y justificado de los reyes de Castilla, como es notorio, y por esta razón debido en los reinos de las Indias desde el tiempo que se hizo la incorporación de los unos con los otros" ${ }^{1}$.

Se trataba de un impuesto aplicado sobre ciertos actos, cuya recaudación en España databa de fines de la Edad Media ${ }^{2}$ y que en América se inició a fines del siglo $\mathrm{XVI}^{3}$. Ella estaba generalmente confiada a oficiales reales ${ }^{4}$, pero en Chile, por cédula de 20 de enero

\footnotetext{
* Profesor de Derecho Administrativo, Pontificia Universidad Católica de Chile. Doctor en Derecho, Universidad de París 1, Panthéon-Sorbonne. Dirección postal: Alameda 340, Edificio de Derecho, Santiago, Chile. Correo electrónico: gbocksan@uc.cl.

1 Recopilación de Leyes de los Reinos de Indias, ley 1a, Tít. XiII, libro VIII.

2 Solórzano y Pereyra (1972) libro VI, capítulo VIII, n 4, expresa que "la primera vez que se comenzó a conceder [la alcabala] fue el año de 1342, reinando el señor rey don Alonso el XI”.

3 Fonseca y Urrutia (1845-1853) tomo II, pp. 6-7; Ots y Capdequí (1969) p. 183.

4 Recopilación de Leyes de los Reinos de Indias, ley 32, Tít. XiII, libro VIII. En torno a los métodos de operación de la alcabala, especialmente en Nueva España, véase Celaya NÁndez (2008).
} 
BOCKSANG HOLA, Gabriel $\square$ La reconfiguración y consolidación de la alcabala en el derecho patrio chileno...

de $1753^{5}$, se otorgó a particulares que hubieran rematado el cobro del tributo. Las alcabalas han atraído la atención principalmente respecto de su situación en la época indiana ${ }^{6}$, y muy particularmente en lo que concierne al llamado "motín de las alcabalas" que manifestó la oposición popular en 1776 a la modificación del régimen concesional del cobro de este tributo $^{7}$, sin perjuicio de otros episodios de agitación ocurridos durante el período tardoindiano $^{8}$.

Por el contrario, el tratamiento jurídico de las alcabalas durante el período patrio no ha sido objeto de un estudio específico; y solo contamos con unos pocos estudios históricos acerca del derecho tributario de esta época ${ }^{9}$, así como con algunos comentarios muy someros sobre este impuesto en obras generales de derecho tributario ${ }^{10} \mathrm{o}$ administrativo ${ }^{11}$.

Es cierto que las alcabalas, como varios de los tributos procedentes de la época indiana, vieron disminuir su influencia económica tras la reestructuración de las finanzas chilenas en los primeros decenios patrios ${ }^{12}$. Este nuevo panorama impositivo se caracterizó por el súbito protagonismo de los impuestos externos, que, durante buena parte de este período, fueron la fuente más importante de ingresos fiscales ${ }^{13}$. Con todo, los antiguos impuestos internos siguieron situándose "dentro de los primeros rangos" de importancia ${ }^{14}$.

En el caso de la alcabala, ella le significó al erario un 2,58\% de los ingresos fiscales totales en 1837 , un $2,72 \%$ en 1850 , y un $3,67 \%$ en $1866^{15}$. Estos montos resultan significativos. Entre los impuestos internos indirectos de este período, la alcabala fue el segundo en importancia económica, solo superada por los aportes al erario derivados del Estanco ${ }^{16}$. Y, en comparación a los impuestos internos directos, la recaudación de la alcabala superó salvo un par de años - a la del catastro, si bien fue inferior a la de los diezmos y a la contribución territorial en los períodos correspondientes ${ }^{17}$.

\footnotetext{
5 Recopilación de Leyes de los Reinos de Indias, edición de la Sala de Indias del Tribunal Supremo, tomo III, p. 75, en la parte final.

6 Existen estudios recientes que abordan, aun tangencialmente, el caso de las alcabalas en la Arica indiana, que no formaba parte del Reino de Chile: Araya Bugueño (2003) y Choque Mariño y Díaz Araya (2016).

7 Barros Arana (2000-2005), T. VI, pp. 258-262; Bravo Lira (1986), p. 98; Carmagnani (1961); Silva Vargas (1972); Villalobos Rivera (1958).

8 Verbigracia, Carmagnani (1961), p. 184, describe otras oposiciones respecto de las alcabalas de la década de 1790.

9 Cattaneo Escobar (2013), Manuschevich Krasmer (1925), Salas Aguilar (2004).

10 Verbigracia, Carvallo Herrera (1961) p. 14.

11 Prado Bustamante (1859) pp. 305-306.

12 López TaVerne (2014) pp. 62 y 99.

13 Jofré, LÜders, Wagner (2000) p. 405: entre 1833 y 1864, los impuestos externos nunca representaron menos del 51\% del total de ingresos fiscales. Solo en 1865 y 1866 bordearon el 40\%, retornando en seguida en 1867 a sus parámetros históricos previos, que se mantuvieron hasta 1879. De acuerdo a López TAVERNE (2014), pp. 106-108, el protagonismo de los impuestos externos se consolidó muy tempranamente; ya en 1818 se transformaron en el principal ramo específico de ingreso, y en 1822 pasaron a constituir más de la mitad de los ingresos totales $(65,9 \%$ de los de ese año).

14 López TAVerne (2014) p. 318.

15 Véase Jofré, LÜders, Wagner (2000) pp. 207 y 309

16 Véase Jofré, LÜDers, Wagner (2000) pp. 306, 309, 312 y 315.

17 Véase Jofré, LÜDers, Wagner (2000) pp. 270, 285 y 309.
} 
Por último, debe tenerse presente que los años más prósperos del período patrio en el aporte fiscal de las alcabalas aún estaban por venir: en términos porcentuales, su máximo se verificó en 1872 , cuando se elevó a casi un $6 \%$ del total general ${ }^{18}$; y, en términos absolutos, su máximo de recaudación acaeció algunos años después, en $1882^{19}$.

El rol de las alcabalas en la construcción del Estado independiente de Chile despertó agitaciones a nivel legislativo y jurisdiccional. Por ello, parece de interés desarrollar algunos aspectos político-jurídicos que aparecen como centrales sobre este tributo, focalizando tal análisis sobre el período que podría llamarse de reconfiguración y consolidación republicana de las alcabalas, extendido desde su recepción por el orden patrio en 1810 hasta las controversias sobre su (re)modelación jurídica durante los diez primeros años de vigencia del Código Civil.

Así, se intentará demostrar que, lejos de tratarse de una institución petrificada, las alcabalas supieron adaptarse a las mutaciones de inicios y mediados del siglo XIX, acompañando la organización económica de Chile $^{20}$ e influyendo sobre la configuración del derecho patrio ${ }^{21}$. Para ello, convendrá examinar dos rubros principales: por una parte, las evoluciones en el tratamiento institucional de las alcabalas (I); y, por otra, las principales dificultades y conquistas que se advierten en la determinación de lo justo referido a las relaciones jurídicas alcabalatorias (II).

\section{LA EVOLUCIÓN DE LAS ALCABALAS HASTA 1866}

No obstante presentar ciertas líneas matrices que se prolongaron en el tiempo, la incorporación y desarrollo de las alcabalas en Chile fue objeto de interesantes debates y sensibles modificaciones. En este contexto, conviene exponer sucesivamente tres etapas principales. Primeramente, la inicial recepción patria de las alcabalas (1.1); en segundo lugar, la restricción del ámbito de las alcabalas, que pudo haber sido más drástica en caso de haber prosperado otros conatos, como el de su supresión (1.2); y, en tercer lugar, una etapa de delineación y especificación de su nueva posición en el derecho tributario republicano (1.3).

\subsection{La RECEPCión de LAS ALCABALAS}

La transición de las alcabalas al régimen patrio, como tantas otras materias jurídicas, resultó primariamente de una adaptación de las instituciones castellano-indianas a la estructura del naciente Estado de Chile. No cabe duda que las alcabalas estaban plenamente en vigor aun en los últimos días de gobierno español, incluida la peculiaridad de que en Chile -como se ha anticipado en la introducción- el cobro del ramo de alcabalas se otor-

18 Díaz, Lüders, Wagner (2016) p. 244.

19 Jofré, LÜDers, WaGNer (2000) p. 309.

20 Campos Harriet (1992) p. 180; Heise González (1959) p. 65.

21 A diferencia de Chile, en otros países, como Perú, las alcabalas, con debidas modernizaciones, existen hasta nuestros días: véase, Verbigracia, Durán Rojo y Mejía Acosta (2014). 
gaba por subasta ${ }^{22}$. Esta solución no les fue detestable a las autoridades asumidas en la revolución de la Independencia, por lo que se perseveró en ella durante los primeros años de gobierno patrio ${ }^{23}$.

La relevancia de las alcabalas en el régimen económico de Chile, que había sido seriamente afectado por la revolución de la Independencia ${ }^{24}$, se advierte al constatarse que ya en 1819 el Senado Conservador aprobó una reglamentación de esta materia. Se trata de dos cuerpos normativos, de estructura bastante sencilla, pero de sistemática algo embrollada.

El primero de ellos, aprobado el 11 de diciembre de 1819, justificaba su aparición señalando que "acercándose el tiempo de las subastas de alcabalas del viento ${ }^{25}$, era necesario designar los legítimos derechos que debían exigirse por los subastadores para que, evitándose el perjuicio del vecindario, se pusiera remedio a los abusos que se causan en la recaudación"26. La ley amalgamaba varias operaciones que respondían a naturalezas diversas. Así, por ejemplo, la norma gravaba el ingreso de ciertas mercaderías a la capital, como charqui (art. 1), sebo y grasa (art. 2), licores (art. 5), o carretadas de madera (art. 8); mientras que, en otras oportunidades, la norma aludía a "la venta diaria de carnes frescas de abasto, vaca, cordero y carnero en la plaza mayor y otros puntos de esta ciudad" (art. 4).

La ley también contenía dos normas generales: una para evitar una doble tributación en caso de que los efectos ingresados fueran a ser remitidos al extranjero, con pago de derechos de aduana (art. 13), y otra para determinar el ámbito territorial en que podía cobrarse el tributo, lo que debía "hacerse en la capital o sus inmediaciones, y no en distancia que pase de media legua, so pena de perder este derecho sus contraventores, a más de otras arbitrarias" (art. 14).

A los pocos días, el 16 de diciembre de 1819, se emitió un segundo texto, complementario del anterior ${ }^{27}$. Esta rápida añadidura puede entenderse por la técnica con que se había concebido el impuesto: gravándose determinados tipos de mercaderías. Así, este nuevo cuerpo normativo sencillamente añadió rubros por los que se debería tributar, encabezados por el que probablemente suscitó el mayor interés económico: el del tabaco, respecto del que la propia ley admitía que se hallaba "hasta ahora libre de todos derechos" (art. 1).

La aplicación de estos reglamentos atrajo rápidamente la avidez de los subastadores de alcabalas. A los pocos meses, ya se contaba con casos de subastadores de fuera de Santiago que pretendieron gravar operaciones referidas a sus respectivas localidades. El Senado

\footnotetext{
22 Real Hacienda con fiadores de Mata Pinilla (1817).

23 Hospital de Mujeres con subastador de alCABalas (1819), GarÍn CON Fisco (1820), GarÍn CON Fisco (1822), Fisco con Olave (1823), Pérez de VAlenzuela con Municipalidad de SAN Fernando (1826).

24 López TAVerne (2014) pp. 97-100.

25 De acuerdo a Montanos Ferrín y Sánchez-Arcilla (1991) pp. 470-471, la expresión "alcabala del viento" designaba a una alcabala complementaria dirigida a gravar "a los comerciantes de otros lugares"; coincide con esta perspectiva general BARROS ARANA (2000-2005) T. XIV, p. 234, al definirla como "impuesto sobre transacciones de especies". Otras fuentes, como Escriche (1891) p. 125, la definen como "la alcabala que adeuda el forastero de los géneros que vende". Como se verá, de los documentos patrios aparece claramente que es la primera acepción, amplia, la que debe preferirse, y no aquella circunscrita a los géneros.

26 Sesiones de los Cuerpos Legislativos (en adelante SCL), III, p. 415; Boletín de Leyes y Decretos del Gobierno (en adelante BLDG) 1819-1820, p. 185.

27 SCL, III, p. 434; BLDG, 1819-1820, p. 187.
} 
se vio forzado a declarar que "el reglamento sobre derechos de alcabalas, dictado el 11 de diciembre último, lo fue solamente para la capital; que el remate de estos derechos se ha realizado en las provincias sobre el pie de lo acostumbrado, agregándose solo la exacción de doce por ciento sobre los tabacos; que por tanto el subastador de La Serena y los demás subastadores de provincias no tienen derecho a efectuar las exacciones, en conformidad al citado reglamento" ${ }^{28}$. Se percibe cómo el Senado aún no lograba separar bien su radicación efectiva en la capital de su vocación nacional, debiendo esclarecer que los reglamentos aprobados lo habían sido solo respecto de Santiago.

Pero el movimiento consolidador de las alcabalas no fue total. También se aprobaron algunas excepciones respecto de su cobro, como la que benefició a partir de 1820 a la orden franciscana. El Senado dispuso que "con lo dictaminado por el Ministerio Fiscal y lo expuesto por la Administración General de Aduanas y Ministros de Hacienda, se conforma el Senado en que se declare la excepción de derechos de alcabala de lo que introduzcan en esta capital los religiosos mendicantes para el gasto y consumo de su comunidad"29.

Por otra parte, la práctica mostraba que el régimen de las alcabalas era en gran parte nominal. "Muchos ciudadanos... hacen compras y ventas de casas, chácaras, etc., y no proceden a extender escrituras por no pagar el derecho de alcabala, contentándose con un papel de seguridad entre partes", con lo que debió disponerse plazos perentorios para pagar las alcabalas insolutas y declararse oficialmente que "será nulo y de ningún valor cualquiera documento de seguridad que a este fin [de eludir el impuesto] hagan, el que no se admitirá en ningún tribunal, quedando el dueño del fundo con todo su derecho, como si no hubiese procedido contrato" 30 .

No ha de sorprender, por lo tanto, que hayan existido impulsos tendientes a suprimir totalmente las alcabalas. En el Congreso Constituyente de 1823, se propuso una ley redactada en los siguientes términos: "Queda abolida toda alcabala interior" ${ }^{31}$. Ella finalmente no prosperó, pero sí dejó de manifiesto la insatisfacción relacionada con este impuesto y sentó las bases para su retroceso.

\subsection{El RETROCESO DE LAS ALCABALAS}

En efecto, poco después se promovería la desaparición de un segmento sensible de las alcabalas: las alcabalas del viento referidas a artículos de abastos ${ }^{32}$. Así, en plena época de agitaciones federalistas, se presentó un proyecto de ley que adjudicaría "las alcabalas a

28 Senado Conservador, 9 de abril de 1820 (SCL, IV, p. 82).

29 Senado Conservador, 28 de enero de 1820 (SCL, III, p. 537).

30 Decreto supremo de 2 de marzo de 1825 (BLDG, II, p. 95).

31 Congreso Constituyente, 3 de octubre de 1823 (SCL, VIII, p. 275).

32 El Director Supremo Ramón Freire le consultó al Congreso Constituyente el 5 de diciembre de 1823 si se debía proceder a subastar nuevamente las alcabalas del viento (SCL, VIII, p. 523). El Congreso Constituyente dispuso los días 6 y 9 de diciembre suprimirse las alcabalas referidas a abastos, y no tomar medidas tributarias complementarias que suplieran el déficit ocasionado (SCL, VIII, pp. 526 y 533). En enero de 1824 el Supremo Gobierno ya lo había comunicado a las autoridades correspondientes a fin de que se dar cumplimiento administrativo a esta orden (SCL, IX, p. 44). Acerca del difícil contexto de esta supresión, véase SAGREDO BAEZA (1997), pp. 301-305. 
los pueblos en los casos de igualdad en las posturas" ${ }^{33}$. Con ello mejorarían las finanzas de estos pueblos -de acuerdo al texto, representados por los cabildos ${ }^{34}$ - y se abría la puerta a desplazar embozadamente el cobro del tributo desde un régimen concesional como el de la subasta a uno de gestión directa por parte de la Administración. Ello en lo inmediato, pues en lo mediato el proyecto apuntaba a que, tarde o temprano, desapareciera esta contribución: "el impuesto vejatorio de la alcabala, entretanto no se extingue, sustituyéndose otro más productivo, debe hacerse lo menos odioso posible a los pueblos y conciliar sus intereses i dignidad con los del Fisco". Este proyecto fue rápidamente tramitado. La Comisión de Hacienda lo informó favorablemente el 11 de agosto de $1826^{35}$ y el Congreso Nacional lo despachó el 20 de agosto del mismo año ${ }^{36}$.

Sin embargo, esto no bastó para acallar las voces contrarias a las alcabalas. Dos años después, se presentó por el Senador Francisco Calderón un nuevo proyecto para suprimir las alcabalas, redactado como sigue: "queda suprimido el impuesto o gabela de las alcabalas desde el último de diciembre del presente año" ${ }^{37}$. La Comisión de Hacienda del Senado lo informó en los siguientes términos: "El impuesto de alcabala es vejatorio y dispendioso; enerva la actividad del tráfico y de la industria; embaraza las transacciones en las cuales tiene relación, y, en fin, la odiosidad a él se aumenta de día en día. La Comisión conviene, en consecuencia, en su extinción, mas no en el tiempo y modo que señala la precedente moción" 38 .

Esta expresión del "tiempo y modo" resultaba crucial, pues una extinción inminente resultaba extemporánea, atentatoria contra los derechos adquiridos de los rematantes, y perjudicial para los intereses del erario. Según la misma Comisión, "el remate de alcabalas se hace por bienios; del actual no va corrido sino un año. Extinguido el impuesto deben rescindirse los diferentes contratos, y darse por consiguiente lugar al justo reclamo que entablará una parte de los contratantes, resultando de esto un perjuicio que no se reparará tal vez con el producto del año que resta. La extinción debe decretarse al vencimiento del remate, para evitar los males que en el caso de la moción sobrevendrían no solo al Fisco sino también a los rematantes". Y, en cuanto al modo, la Comisión advirtió acertadamente que "hay diferentes alcabalas y diferentes objetos también afectos a este impuesto que deben regularizarse con claridad en varios artículos". No bastaba con suprimir el impuesto de alcabala en abstracto, pues las alcabalas eran, a la sazón, múltiples.

Lo cierto es que ese proyecto no prosperó, como tampoco lo hizo uno que, sucesivamente, debía introducir el Ministro de Hacienda en su reemplazo ${ }^{39}$. El 9 de septiembre de 1829 fue presentado un nuevo proyecto en este sentido. En su preámbulo, sus promotores

\footnotetext{
33 Congreso Nacional, 28 de julio de 1826 (SCL, XII, p. 258). Artículo 1: "Los pueblos, a quienes convenga la administración de la alcabala, serán preferidos por el tanto que otro diere".

34 Artículo $2^{\circ}$ : "Los Cabildos, con quienes se entenderá el artículo anterior, se obligarán en la forma más solemne al cumplimiento de la subasta".

35 SCL, XII, p. 349.

36 SCL, XII, p. 436. El texto no aparece en BLDG.

37 Cámara de Senadores, 27 de octubre de 1828 (SCL, XVI, p. 376).

38 Comisión de Hacienda del Senado, 5 de noviembre de 1828 (SCL, XVI, p. 392).

39 Cámara de Senadores, 24 de noviembre de 1828 (SCL, XVI, p. 451).
} 
subrayaban que "los derechos de alcabalas e impuesto sobre viñas que pagan hoy los pueblos, son los que más pesan sobre ellos, no tanto por las cantidades que erogan, cuanto por las vejaciones que sufren y la desproporción en el reparto", añadiendo que "el ingreso que ellos proporcionan al Erario público es, por otra parte, demasiadamente corto". El texto propuesto era muy sencillo: un artículo por el quedaban "abolidas las alcabalas llamadas del viento e impuesto sobre viñas" y otro, de resguardo de los derechos adquiridos, por el que "lo dispuesto en cuanto a las alcabalas es sin perjuicio de los remates que estuviesen hechos, pues éstos continuarán hasta el cumplimiento del término estipulado" ${ }^{30}$.

La Cámara alcanzó a discutir y aprobar el texto antedicho, con algunas modificaciones: un primer artículo declaraba abolido el impuesto sobre licores, un segundo artículo suprimía las alcabalas del viento y protegía los derechos de los subastadores por el lapso rematado, y un tercer artículo mandaba promover un proyecto que llenase el déficit económico producido por la desaparición de estos tributos ${ }^{41}$. Del texto se dio cuenta ante el Senado ${ }^{42}$, y la Comisión de Hacienda informó que el Senado debía aprobar "en todas sus partes" el proyecto remitido por la Cámara de Diputados ${ }^{43}$, pero no llegó a concluir su tramitación, sumergido el país y las Cámaras Parlamentarias en importantes agitaciones políticas.

Transcurrida la guerra civil de 1829-1830, el asunto no se reactivó sino hasta $1831^{44}$. El Ejecutivo presentó el 11 de octubre ante la Cámara de Diputados un proyecto integral de reforma tributaria ${ }^{45}$. Ya al día siguiente, la Comisión de Hacienda de esta Cámara informaba que "considerando lo benéfico de esta disposición y la moderación con que en ella se trata de llenar el déficit que debe resultar en el Erario, está decidida por la sanción del proyecto" ${ }^{\prime 6}$. El texto fue aprobado por la Cámara de Diputados el 15 de octubre con ligeras modificaciones en sus artículos $4^{\circ}$ y $8^{\circ 47}$, y por el Senado el 18 de octubre, conformándose totalmente a la redacción que le había sido remitida desde la otra cámara parlamentaria ${ }^{48}$. Así, el proyecto fue aprobado en apenas una semana contada desde su presentación original.

Esta ley logró, por primera vez, reestructurar la arquitectura tributaria durante la época patria. Abolió el impuesto sobre licores, el derecho de cabezón, y "las alcabalas subastadas" ${ }^{49}$, disponiendo que el déficit que originaría esta extinción fuera cubierto por un nuevo tributo: el catastro, un impuesto territorial que produciría "la cantidad de cien mil

40 Cámara de Diputados, 9 de septiembre de 1829 (SCL, XVII, p. 365).

${ }^{41}$ Cámara de Diputados, 24 de octubre de 1829 (SCL, XVII, p. 437).

42 Cámara de Senadores, 26 de octubre de 1829 (SCL, XVIII, p. 171).

43 Comisión de Hacienda de la Cámara de Diputados, 30 de octubre de 1829 (SCL, XVIII, p. 182).

44 En 1830 solo se promovió un texto que concernía el impuesto de licores: la propuesta del Ejecutivo se presentó el 21 de agosto ante el Congreso de Plenipotenciarios (SCL, XVIII, p. 433) y el 22 de septiembre se dio cuenta de un informe favorable al proyecto (SCL, XVIII, p. 485).

45 Cámara de Diputados, 11 de octubre de 1831 (SCL, XX, p. 309).

46 Comisión de Hacienda de la Cámara de Diputados, 12 de octubre de 1831 (SCL, XX, p. 318).

47 SCL, XIX, p. 269.

48 SCL, XIX, p. 277.

49 Ley de 18 de octubre de 1831 (BLDG, V, p. 174) art. $1^{\circ}$. 
pesos anuales" gravando a "todos los predios rústicos de la República"50 "en razón proporcional a los productos de cada predio" ${ }^{1}$. Como se advierte, el impuesto territorial nació en Chile so pretexto de sustituir a la alcabala; y este último impuesto, calificado en esta época como vejatorio, aparentaba desaparecer definitivamente. Empero, la realidad mostró ser más compleja.

\subsection{LA ESPECIFICACIÓN Y ESTABILIZACIÓN DE LAS ALCABALAS}

La ley de 18 de octubre de 1831 no suprimió totalmente a las alcabalas. Sí dispuso, como ya se ha explicado, la desaparición de las "alcabalas subastadas" 52 . Pero la misma ley preceptuó de modo explícito la subsistencia de "la alcabala de contratos", la que "quedará reducida del 6 al $4 \%$ en la venta de los fundos rústicos y urbanos, y al 3 en los sitios eriales de las poblaciones". Y el mismo artículo dispuso en definitiva la absorción de estos tributos en el seno de la Administración: del régimen de subastas, se pasaba a cobrar "en lo sucesivo íntegramente por las aduanas, o por las tenencias de ministros en las provincias donde no existiesen establecimientos de aquella renta" ${ }^{53}$.

La ley también contaba con una norma transitoria por la que se expresaba que "solo tendrá efecto lo dispuesto en los artículos $1^{\circ}$ y 17 cuando se haya hecho el repartimiento del catastro que debe subrogar a las contribuciones extinguidas" 54 . En otros términos, debía esperarse hasta el vencimiento del plazo de las subastas de las contribuciones que eran derogadas por la ley para que entrara en vigor el nuevo régimen tributario. $\mathrm{Al}$ poco tiempo, el Gobierno se percató de que esta medida podía entrabar, aun judicialmente, la operatividad de las nuevas disposiciones. Así, por un mero decreto -lo que resultaba asaz cuestionable en lo jurídico- se dispuso el 26 de octubre de 1832 que "desde el $1^{\circ}$ de enero de 1833 tendrá cumplido efecto en toda la República la ley de 18 de octubre de 1831, y quedarán extinguidas las gabelas llamadas alcabalas del viento, impuesto sobre licores y derechos de cabezón", quedando a firme, como estaba previsto, las alcabalas de contratos" ${ }^{55}$. La importancia que este decreto revestía para el Supremo Gobierno aparece de la muy intensa medida de publicidad que se dispuso para su conocimiento por la población: "para que este decreto llegue a noticia de todos se publicará por bando en las poblaciones, y se leerá por tres domingos consecutivos después de misa mayor en las parroquias y viceparroquias rura-

\footnotetext{
50 LEY DE 18 DE OCTUBRE DE 1831 , art. $2^{\circ}$.

51 LEY DE 18 DE octubre DE 1831 , art. $3^{\circ}$.

52 Ley de 18 DE octubre De 1831, art. $1^{\circ}$. Pero debe tenerse en cuenta que, al menos análogamente, las alcabalas suprimidas revivirían bajo la forma de la sisa, un impuesto municipal que fue penetrando progresivamente en distintos lugares del territorio nacional, hasta beneficiarse de una recepción general por ley de 31 de julio de 1860 (BLDG, XXVIII, p. 189).

53 Ley de 18 de octubre de 1831, art. 17. Durante la década de 1820, las Tesorerías se mostraron reticentes e incluso negativas a intervenir en cuestiones de esta naturaleza, de lo que puede desprenderse que la norma de la ley de 1831 fue ligeramente expansiva. Por ejemplo, un informe de los Ministros del Tesoro de 5 de mayo de 1826 expresaba que "esta Tesorería no tiene en qué entender en lo referente a derechos de alcabala, pues todo lo anexo a este ramo es privativo de la Aduana general” (Archivo de la Real Audiencia, volumen 2402, pieza 5, f. 14).

54 LEY DE 18 DE OCTUBRE DE 1831, art. 18.

55 Decreto Supremo de 26 de octubre de 1832 (BLDG, V, p. 269) art. $2^{\circ}$.
} 
les, circulando al efecto los Intendentes órdenes positivas a los gobernadores locales, y a los respectivos párrocos" 56 .

La estatización de las alcabalas no parece haber originado mayores turbulencias entre los particulares. Por lo demás, las autoridades políticas fueron hábiles en torno a evitar dichos riesgos, favoreciendo a los contribuyentes con reducciones en los montos adeudados. Un decreto supremo de 1832 preceptuó que, transitoriamente, "se cobrará por alcabala que se adeude al Fisco por ventas hechas antes, o que se hicieren en los términos fijados por este decreto, un 3\%" 57 .

Pero esta estatización no estuvo exenta de inconvenientes. En 1833, el Supremo Gobierno emitió un decreto destinado a especificar el modo de liquidación y cobro de la alcabala, advirtiendo que los perjuicios del Fisco "se acrecientan en los departamentos, subdelegaciones y distritos distantes de las capitales de provincia, por falta de agentes autorizados para recaudar dicho derecho". En esta época, en efecto, el aparato estatal aún se hallaba insuficientemente desarrollado como para lograr una cobertura suficiente en la recaudación de las alcabalas. Por ello, se dispuso que "los Tenientes de Ministros autorizarán, bajo su inmediata responsabilidad, a un individuo que reúna las calidades necesarias para percibir el derecho de alcabala de contratos en cada distrito de los que comprenda su jurisdicción" 58 . Se advierte que la satisfacción directa de la necesidad pública era imposible en estas circunstancias; y sin regresar a la lógica concesional abandonada en 1831, se estaba optando por una lógica cercana a la funcionarial.

El paso definitivo en la especificación del régimen patrio de las alcabalas se dio en 1835. Como se ha explicado, la ley de 1831 había suprimido las alcabalas subastadas y había declarado la subsistencia de las alcabalas de contratos, señalando los porcentajes que se deberían en ciertas ventas de predios rústicos, de predios urbanos y de sitios eriazos. Surgió, sin embargo, la duda de si otras alcabalas de contratos se hallaban subsistentes, pues una cosa era que no se les estableciera expresamente en la ley ninguna tasa aplicable, y otra era que ellas hubieran sido efectivamente suprimidas, declaración que la ley de 1831 no contenía.

El 2 de febrero de 1835 se presentó ante la Cámara de Diputados un nuevo proyecto de ley, motivado en el hecho de que la ley de 1831, "no habiendo expresado terminantemente si en la venta de los demás bienes se adeudaba este derecho, produjo fundadas dudas que han embarazado a las oficinas recaudadoras al tiempo de exigir la alcabala sobre venta de propiedades libres de todo gravamen, en el concepto de unos, y sujetas al pago del antiguo derecho según el juicio de otros". Casos en que subsistía la duda eran los de los de los buques y de las minas, pues "siendo evidente que entre esta clase de bienes hay unos como las minas cuyo valor es imaginario y que sin embargo reciben con frecuencia la más alta apreciación; y otros como los buques, que pueden eludir el pago de un derecho subido con

56 Decreto Supremo de 26 de octubre de 1832, art. $4^{\circ}$.

57 Decreto Supremo de 15 de junio de 1832 (BLDG, V, p. 177).

58 Decreto Supremo de 26 de junio de 1833 (BLDG, VI, p. 64), art. $1^{\circ}$. 
salir de nuestros puertos y celebrar en país extranjero las escrituras de venta, la más sencilla previsión aconseja moderar el impuesto para hacerlo productivo" 59.

La tramitación de este proyecto fue bastante expedita, y el 17 de marzo de 1835 entró en vigor como ley de la República ${ }^{60}$. De su texto se advierte que la principal preocupación sistemática fue la de concebir a las alcabalas como debidas solamente en aquellas operaciones enunciadas por la ley, circunscribiendo su alcance e impidiendo cualquier interpretación extensiva a su respecto. Así, establecía los bienes que eran sujetos a gravamen: "la alcabala de contratos solo se exigirá de las propiedades o bienes que a continuación se expresan: $1^{\circ}$ De fundos rústicos o urbanos; $2^{\circ}$ De sitios eriales situados dentro del área o contiguos a las poblaciones; $3^{\circ}$ De minas i de buques" ${ }^{61}$, quedando "libres del pago de alcabala, los bienes no comprendidos en la nomenclatura que contiene el artículo primero" ${ }^{62}$.

Por otra parte, no toda operación sobre estos bienes se hallaba sujeta a la contribución. El derecho debía pagarse "cada vez que transfieran dominio los referidos bienes, sin otras excepciones que las establecidas por las leyes, y en los casos que ellas determinan", debiendo también pagarse en "los contratos de arrendamientos que excedan de diez años" 63 .

En cuanto a las tasas aplicables, fueron mantenidas las que habían sido establecidas en 1831 -un $4 \%$ en fundos rústicos y urbanos y un 3\% en los eriales- pero se añadió el $2 \%$ sobre las minas o buques ${ }^{64}$. Por su parte, los capitales acensuados a partir de la promulgación de la ley con cualquier objeto, pagarían el $5 \%$ por derecho de imposición ${ }^{65}$ que, como se verá más adelante, era distinto del de alcabala, no obstante estar contenido en esta ley.

Por último, cabe destacar que -siguiendo y ampliando el caso de los franciscanos, introducido a inicios del período patrio y referido más arriba- la ley eximió del pago de alcabalas a "los fundos rústicos o urbanos pertenecientes a escuelas de enseñanza primaria, colegios de educación, casas de expósitos, hospicios, hospitales y demás establecimientos de caridad" 66 .

Estas disposiciones sintetizaron el marco fundamental de las alcabalas, y por décadas no sufrirían alteraciones graves. Ello sin perjuicio de ciertos ajustes circunstanciales, como el de la ley que dispuso la exención de la alcabala "por las ventas y permutas" de "predios urbanos y sitios eriales” en Talca, Maule y Concepción durante 1835, 1836 y 1837 con

\footnotetext{
59 SCL, XXIV, p. 2.

60 BLDG, VI, p. 193.

61 LEY DE 17 DE MARZO DE 1835 , art. $1^{\circ}$.

62 LEY DE 17 DE MARZO DE 1835, art. $4^{\circ}$. Originalmente este artículo se refería exclusivamente a los contratos de venta: "Quedan libres del pago de alcabala los contratos de venta que se hagan de cualesquiera bienes no comprendidos en la nomenclatura que contiene el artículo primero" (SCL, XXIV, p. 2). Fue la Cámara de Senadores la que simplificó la redacción y extendió el alcance de la exención de alcabala en el sentido del texto final (SCL, XXIII, p. 275).

63 LEY DE 17 DE MARZO DE 1835, art. $3^{\circ}$. El caso de los arrendamientos no procedía del proyecto original, y fue añadido por la Cámara de Senadores (SCL, XXIII, p. 275).

64 LEY DE 17 DE MARZO DE 1835 , art. $2^{\circ}$.

65 LEY DE 17 DE MARZO DE 1835 , art. $6^{\circ}$

66 LeY de 17 DE MARZo de 1835, art. 5. A más de ello, de acuerdo al artículo $7^{\circ}$ estaban exceptuadas de imponer las fundaciones que se hicieran en beneficio de estas entidades.
} 
ocasión del terremoto de 20 de febrero de $1835^{67}$; el de la ley interpretativa del artículo $6^{\circ}$ de la ley de 17 de marzo de $1835^{68}$; el del decreto supremo que especificó la procedencia del pago de alcabalas por fragmentos de buques náufragos ${ }^{69}$; y el del decreto supremo confirmatorio de un decreto de 12 de noviembre de 1835 por el que se subrayaba no deberse alcabalas en la traslación de capellanías ${ }^{70}$.

Quizás la alteración orgánica más sustantiva fue la del decreto supremo de 10 de noviembre de 1842, por el cual se encomendó el cobro de la alcabala a la Factoría General del Estanco y a sus administraciones subalternas, dejando, por lo tanto, de ser su cobro de competencia de aduanas y tesorerías ${ }^{71}$. Pero, como bien puede advertirse, esta modificación en cuanto a las atribuciones no alteraría directamente su régimen jurídico, que, desde la época de la Emancipación hasta los diez primeros años de vigencia del Código Civil chileno, seguiría ciertas líneas bastante estables, a pesar de sufrir ajustes derivados de las modificaciones en el derecho de la época.

\section{LOS CONFLICTOS JURÍDICOS SOBRE LAS ALCABALAS}

Las vicisitudes institucionales de la incorporación de las alcabalas al régimen patrio estuvieron jalonadas por interesantes problemas en puntos específicos de derecho. A nuestro juicio, sobresalen cuatro aspectos de interés práctico. Uno, más bien preliminar, que fue la identificación de la órbita operativa de la alcabala (2.1), y tres derivativos, pero de poderoso interés práctico: la determinación de su hecho generador (2.2), el régimen de su pago (2.3), y el tratamiento de la acción destinada a su cobro, principalmente respecto de su prescripción (2.4).

\subsection{LOS LÍMites de la APLiCACión DE LA ALCABALA}

De la evolución histórica recién expuesta puede intuirse que existió una evolución en los criterios de determinación de qué tipos de operaciones, en abstracto, constituían alcabala. Como se ha advertido, hasta la ley de 18 de octubre de 1831, las cosas sobre las que este impuesto podía recaer eran múltiples, y no solo restringidas a los bienes raíces. Así, entre 1820 y 1830 , en sede jurisdiccional, puede hallarse ejemplos de controversias concernientes a alcabalas de ventas de ganados ${ }^{72}$, espejos ${ }^{73}$ e inmuebles $^{74}$.

Esta dispersión de objetos no debiera entenderse como una flexibilidad total en el ámbito alcabalatorio. Ciertamente, las autoridades eran libres para determinar qué bienes se hallaban gravados; pero no lo eran tanto como para soslayar el hecho de que estos tributos estuvieran sometidos a un criterio de normatividad estricta. Los dos reglamentos-leyes

67 Ley de 22 de octubre de 1835 (BLDG, VI, p. 214), art. $2^{\circ}$.

68 Ley de 19 de diciembre de 1842 (BLDG, X, p. 400).

69 Decreto supremo de 10 de noviembre de 1843 (BLDG, XI, p. 197).

70 Decreto supremo de 29 de marzo de 1851 (BLDG, XIX, p. 177).

71 BLDG, X, p. 345.

72 Campos con Hacendados del Partido de RanCaGua (1822).

73 EXPEDIENTE SOBRE ALCABALA DE ESPEJOS (1827).

74 FISCO CON ÁVILA (1830). 
de 1819 muestran este aspecto con toda nitidez: la alcabala se debería exclusivamente respecto de las operaciones y los bienes allí señalados ${ }^{75}$; y ello solo respecto de Santiago, salvo la excepción de la alcabala del tabaco, extendida al resto del territorio nacional por expresa disposición del Senado Conservador ${ }^{76}$. Ello no era sino un sarmiento del principio de legalidad tributaria, que, como bien se ha apuntado, se introdujo con rango constitucional a partir de 1812 y pervivió en las cartas fundamentales posteriores ${ }^{77}$.

Con todo, durante la década de 1810 y la primera mitad de la de 1820 este reconocimiento del principio de normatividad estricta de las hipótesis de bienes y operaciones que adeudaban alcabala parece haber implicado alguna matización. En efecto, los Ministros de Aduana, por informe de 1824 dirigido al Ministro de Hacienda, sostuvieron que "desde que se subastan las alcabalas que se denominan de viento, que a esta fecha hace treinta y un años, siempre se ha comprendido en los remates de ellas el derecho de cabezón en esta y demás provincias, sin que en esto haya habido alteración alguna. Si en las provincias o partidos ha habido descuido en el cobro de cabezón, habrá sido culpa del subastador y en su perjuicio. Mas, esto en nada perjudica a la hacienda pública, porque respecto de ella los subalternos cumplen su deber por sí o su fiador"78.

Esta eventual flexibilidad de origen consuetudinario parece haberse terminado en 1826, con una sentencia Pérez de Valenzuela. Los hechos de la causa eran relativamente sencillos: el subastador de alcabalas pretendía cobrarles a los habitantes de San Fernando el impuesto de carnes muertas. La vista fiscal de Francisco Antonio Elizalde era manifiestamente proclive a que se le permitiera el cobro, dado que "si los anteriores subastadores han sido generosos respecto del pueblo [no cobrando el tributo], no es una ley para obligar a este a que haga lo mismo"79, opinión que siguió el juez de letras al decidir que el subastador de alcabalas podía cobrar tanto el tributo por ventas de animales vacunos como el correspondiente a carnes muertas ${ }^{80}$. Pero la Corte de Apelaciones no se conformó con esta decisión y la revocó, entendiendo "que el subastador de alcabalas de San Fernando, no debe cobrar el derecho de carnes muertas, ni de ninguno otro artículo, que no esté expresamente comprendido en las condiciones de su remate" 81 .

En otras palabras, la normatividad era entendida en un sentido doble: solo podría subastarse los derechos establecidos expresamente por la ley, con lo que se apuntaba a un principio de legalidad, y solo podía exigirse los derechos mencionados expresamente en el acta de remate. Poco después, la Corte de Apelaciones ahondó en este criterio, pues repi-

\footnotetext{
75 BLDG, 1819-1820, pp. 185 y 187.

76 SCL, IV, p. 82.

77 Avilés Hernández (2005) pp. 70-72. A más de los documentos señalados allí, debe añadirse el caso del Acta de Unión de 1823 (BLDG, I, p. 21; SCL, VII, p. 33), por cuanto su artículo $4^{\circ}$ disponía que "las atribuciones del Poder Ejecutivo hasta la nueva Constitución que forme el Congreso serán las mismas de la Constitución provisoria del año de 1818, en todo lo que no contradigan estas instituciones”, con lo que la legalidad tributaria debía entenderse protegida tal como lo había sido en la referida Carta de 1818.

78 Informe de 11 de junio de 1824 (SCL, IX, p. 427).

79 Vista fiscal de 2 de mayo de 1826 (Archivo de la Real Audiencia, volumen 2402, pieza 5, f. 13 vta.).

80 Archivo de la Real Audiencia, volumen 2402, pieza 5, f. 14 vta.

81 Pérez de VALENZUELA CON MUNiCipALIDAd DE SAN FERNANDo (1826).
} 
tiendo la estricta sujeción al remate de las alcabalas, reavivó el aspecto territorial, prescribiendo que el subastador "no puede excederse de las condiciones puestas para el remate de las de la capital ni extenderse a ramos no comprendidos en ella ni a la exacción en más distancia que la prevenida por la ley" ${ }^{\prime 2}$. En otras palabras, la esfera territorial del remate debía entenderse estrictamente, y no podía ampliarse por la voluntad del subastador del cobro de los tributos.

Fundado abstractamente en normas constitucionales, e insertado decisivamente en la práctica a través del ámbito de las alcabalas, este movimiento tendiente a la normatividad estricta de los impuestos terminaría consolidándose rápidamente en el espectro nacional. En 1832, la Corte Suprema destituyó al Gobernador de Curicó y a varios municipales por haber introducido una contribución sin previa autorización legal ${ }^{83}$, decisión que puede haber sido relevante para la introducción de la norma del artículo 160 de la Constitución de 1833 y su énfasis en el carácter expreso de las atribuciones en el régimen chileno de derecho público ${ }^{84}$. El alcance de esta perspectiva estricta se extiende al día de hoy, en que se reconoce sin ambages que la ley "es fuente única de la obligación tributaria" 85 .

Pero hay más. Durante la década de 1840 surgió otra controversia que comprometía, al menos implícitamente, los límites de aplicación de este tributo. El artículo $6^{\circ}$ de la ley de alcabalas de 17 de marzo de 1835 había dispuesto que "todo capital que después de la promulgación de la presente ley se imponga a censo, ya sea para fundar capellanías eclesiásticas o laicales, ya sea con cualquier otro objeto, pagará el cinco por ciento por derecho de imposición”.

Brotó entonces la duda de si en estos negocios, dado que el derecho de imposición estaba tratado dentro de la ley de alcabalas, los hechos gravados con aquel debían también el pago de alcabala. La cuestión, grave desde un punto de vista sistemático, tenía raigambre histórica. Antes de la promulgación de la ley de alcabalas, en 1833, la Corte de Apelaciones había juzgado que ambos eran conjuntamente exigibles, estimando que "a más de los derechos de imposición, deben igualmente cubrirse los respectivos de alcabala" ${ }^{86}$. Con mayor razón podía entenderse, luego de la entrada en vigor de la ley de 1835, que ambos tributos podían gravar una misma operación.

El 4 de junio de 1841 se presentó ante la Cámara de Diputados una moción legislativa destinada a fijar la verdadera inteligencia del citado artículo ${ }^{87}$. En su preámbulo se explicaba que el tenor de la ley parecía apuntar a que "se cobre alcabala cada vez que transfieran dominio los referidos bienes en su artículo $2^{\circ}$, entre los que no se enumeran los censos", y como estos no transfieren dominio "es claro que el censo por sí solo no adeuda alca-

\footnotetext{
82 BARRIL CON FISCO (1828).

83 Contra de la PeÑa y otros (1832). La vista fiscal de Mariano Egaña (14 de marzo de 1832) expresaba nítidamente que "El tercer crimen es el haber impuesto una contribución a varios vecinos de Curicó, arrogándose así la facultad exclusiva que corresponde al Congreso Nacional por el párrafo $3^{\circ}$ artículo 46 de la Constitución”. 
bala, sino solo su derecho específico que la misma ley le impone, de un cinco por ciento". De acuerdo a este preámbulo, tal había sido la posición de los fiscales; pero la Contaduría Mayor había formulado otra interpretación, decidiendo "por la misma ley que se cobre la alcabala a más del derecho de imposición en cada censo".

El proyecto suscitó interés. Al tramitarse en el Senado, el propio Andrés Bello concurrió con una versión de su pluma, consistente en cuatro artículos que excedían el carácter interpretativo de la ley, regulando ampliamente el derecho de imposición ${ }^{88}$. Al regresar a la Cámara de origen, su Comisión de Hacienda rechazó vehementemente el texto aprobado en el Senado, deplorando que "la Cámara de Senadores, desnaturalizando la cuestión, acuerda una nueva ley que no se le ha pedido y que no ha podido dictar constitucionalmente", habiendo debido, a lo sumo, "volverlo y no ocurrir al arbitrio de que se entendiese adicionado o corregido el proyecto que no ha considerado". La Comisión fue de opinión "que debe pasar segunda vez el proyecto de ley a la Cámara de Senadores para que lo apruebe o deseche" ${ }^{89}$, lo que fue seguido por la Sala, que rechazó lo obrado por el Senado por una fuerte mayoría de 33 contra $1^{90}$.

Trasegada la cuestión nuevamente al Senado, este cedió a fines de 1842 frente a los reparos expresados y "resolvió invitar a la Cámara de Diputados a que nombre una comisión de su seno que reunida con otra del Senado procure poner término a la divergencia de opiniones en este punto" 91 , la que fijó el texto definitivo por ley de 19 de diciembre de 1842. Esta finalmente consagró una ley propiamente interpretativa, que declaraba que la imposición del 5\% "es el único derecho que ha debido cobrarse y en lo sucesivo se cobrará a los capitales que desde la promulgación de la ley se hubiesen impuesto o después se impusiesen con los expresados fines" ${ }^{\prime 2}$.

Así, se fijó el criterio de que el mero hecho de hallarse enunciado un determinado acto o contrato en una ley principalmente referida a un tributo no bastaba para que este lo gravara, si la ley disponía explícitamente en ella un tributo especial al que tal acto o contrato se hallara sujeto. Como puede advertirse, esto también es manifestación del principio de legalidad tributaria. En definitiva, por más que se encontraran textualmente designadas en la ley de alcabalas de 1835, las operaciones gravadas con el "derecho de imposición" ni debían alcabala ni eran calificables como alcabala ${ }^{93}$.

\footnotetext{
88 Cámara de Senadores, 24 de septiembre de 1841 (SCL, XXIX, p. 339).

9 Cámara de Diputados, 8 de octubre de 1841 (SCL, XXVII, p. 512)

9 Cámara de Diputados, 11 de octubre de 1841 (SCL, XXVII, p. 515)

1 Cámara de Senadores, 28 de octubre de 1842 (SCL, XXXI, p. 238).

2 BLDG, X, p. 400.

93 Con todo, la asociación imposición-alcabala era tan fuerte que, de acuerdo a la Gaceta de los Tribunales, algunas carátulas de expedientes concernientes al derecho de imposición eran calificadas como alcabala: Verbigracia, CALlejas con FisCo (1846).
} 


\subsection{El HECHO GENERADOR DE LA ALCABALA}

Más allá de la constatación general de que "la alcabala era una contribución que gravaba la circulación física, el tráfico de mercancías" ${ }^{4}$, y que las leyes definían cuándo esta circulación se estimara como relevante -como en el caso paradigmático de las transferencias del dominio de inmuebles-, la determinación de criterios de justicia en torno al hecho generador de la alcabala no siempre fue sencilla, y la judicatura nacional debió abordarla en múltiples ocasiones. En este sentido, la resolución de controversias relacionadas con este impuesto permitió perfeccionar la identificación de casos de enriquecimiento injusto en el derecho chileno.

Ciertamente, el impuesto de alcabala no se generaba por bien, sino por actos celebrados sobre el bien, y por consiguiente podía llegar a pagarse múltiples veces por cada bien: "la alcabala se adeuda cuantas veces se vende la especie sea mueble, semoviente o res hasta que se consume" 95 . Por lo mismo, si operaban dos actos gravables sucesivos, se debían dos alcabalas $^{96}$.

Pero la identificación precisa del hecho generador padeció mutaciones, que reflejan las variaciones de tratamiento que distintas instituciones jurídicas tuvieron en esta época. En esta materia se advierte un punto de inflexión en la entrada en vigor del Código Civil.

Hasta 1856 inclusive, se reconoció la primacía del carácter consensual del contrato de compraventa, que era el de mayor relieve práctico entre los que podían ser gravados con la alcabala. Con ello, la alcabala se debía si había operado un acuerdo entre las partes, aun cuando no se hubiera extendido escritura alguna. Ello resulta particularmente llamativo tratándose de inmuebles, situación que una sentencia de 1830 debió enfrentar. La vista fiscal, de algunos años antes, sostenía que "la Hacienda denominada Pichi fue vendida a Ávila en cinco mil pesos, y que consta por instrumento otorgado, ya citado, en treinta de enero de mil ochocientos diez: aunque no lo hubiera, ya se sabe que la escritura no es de esencia del contrato, ni se requiere, sino únicamente para la constancia, según la ley, a menos que el otorgamiento de la escritura, se ponga por condición esencial, que perfeccione el contrato" ${ }^{\prime 7}$. El tribunal siguió al fiscal y entendió que la venta ya se había perfeccionado, con todas las consecuencias jurídicas correspondientes ${ }^{98}$. Tras la entrada en vigor de la ley de 1835, el criterio se mantuvo imperturbable: "estando perfecto el contrato no se necesita la celebración de escritura para fijar su naturaleza", debiéndose así el pago de alcabala99.

A partir de 1857, con la entrada en vigor del Código Civil y del régimen de posesión inscrita, el criterio resultó modificado. Por cierto, nunca dejó de entenderse que la existen-

94 PASTOR (1977) p. 2.

95 Informe de los Ministros de Aduana, de 6 de mayo de 1826 (f. 14 vta.) en el expediente PÉREZ DE VALENZUE-

LA CON MUNICIPALIDAD DE SAN FERNANDO (1826).

96 SOFFIA CON FISCO (1865).

97 Vista fiscal de 11 de junio de 1824 (Archivo Judicial de Santiago, volumen 643, pieza 2, f. 43 vta.).

98 FisCO CON ÁVILA (1830).

99 SOSA CON FISCO (1842). 
cia de un contrato fuera indispensable para que el tributo fuera exigible ${ }^{100}$, por lo que el mero proyecto de un contrato no engendraba ninguna obligación tributaria ${ }^{101}$.

Pero, como se sabe, la lógica consensual del contrato de venta de bienes raíces fue abandonada por el Código Civil, transitándose a una lógica formal en aplicación de su artículo 1801: "La venta de los bienes raíces, servidumbres y censos, y la de una sucesión hereditaria, no se reputan perfectas ante la ley, mientras no se ha otorgado escritura pública”. Así, aun existiendo consentimiento, sin escritura pública no había compraventa, y por lo tanto no se debería la alcabala ${ }^{102}$. En esto, el aspecto de la suscripción de la escritura resultaba fundamental: a falta de firma, tratárase de las de ambas partes ${ }^{103}$ o solamente de la de una ${ }^{104}$, el Fisco no podía exigir suma alguna.

No cabiendo dudas sobre el hecho de que sin la escritura pública del contrato de compraventa de bienes raíces no se debería alcabala, surgió la cuestión de si la escritura pública era suficiente para que surgiera la obligación de pagarla. El problema revestía complicaciones porque el Código Civil introdujo el régimen de la posesión inscrita, por el cual "se efectuará la tradición del dominio de los bienes raíces por la inscripción del título en el Registro del Conservador" 105 . El artículo $3^{\circ}$ de la ley de alcabalas de 1835 disponía que "este derecho deberá pagarse cada vez que transfieran dominio los referidos bienes", por lo que era esperable que se produjera controversia acerca de si una compraventa extendida por escritura pública pero no inscrita pudiera adeudar la alcabala, dado que la escritura no bastaba para transferir el dominio.

La especie crucial en este ámbito procede del año 1865. En ella, el juez de letras entendió que la alcabala se debería una vez inscrito el título, toda vez que "para que se adeude alcabala no basta celebrar y perfeccionar un contrato capaz de transferir el dominio, ni ejecutar cualquier otro acto, aunque sea la misma entrega de la especie y de su precio, sino que es indispensable que haya transferencia de dominio, la cual se verificaba antes con la entrega y ahora con la inscripción del título conforme al art. 686 del Código Civil” ${ }^{106}$. Sin embargo, la Corte Suprema revocó la sentencia anterior ${ }^{107}$, lo que resulta bastante sorprendente ante la claridad de las normas del Código.

La explicación es una sola: la pervivencia de normas y criterios del derecho castellano-indiano. La Corte expresó en el considerando cuarto que "según lo dispuesto en la Real Cédula de 5 de setiembre de 1791, se debe alcabala desde que es irrevocable el contrato

\footnotetext{
100 PADILLA CON FiSCO (1862).

101 OSSA CON FISCO (1865).

102 Heatley Evans y Ca. con Fisco (1864).

103 SChWARUmberG CON FisCo (1861), OCAMPO CON FisCo (1865), HERMidA CON FisCo (1866).

104 LIRA CON FISCO (1866).

105 Código Civil, artículo 686. En cursivas en el original.

106 Álamos con Fisco (1865). Soffia CON FisCo (1865), de un mes antes, lidiaba con esta cuestión, pero mezclada con otras consideraciones y sin la nitidez de la sentencia posterior.

107 Y revirtió el criterio que podía desprenderse de una especie de algunos años antes, Vargas con Fisco (1861), que giraba en torno a un contrato de donación. La sentencia del juez de letras, confirmada por la Corte Suprema, recogía el criterio de la inscripción como requisito para el pago de la alcabala, pero además se fundaba en la nulidad del acto por muerte civil del donatario, con lo que -a la luz de la jurisprudencia posterior- podría entenderse que este último motivo hubiera sido el determinante para que se eximiera del cobro del tributo.
} 
traslaticio de dominio". La invocación de esta disposición es tanto más sorprendente si se tiene en cuenta que se halla frontalmente opuesta al artículo $3^{\circ}$ de la ley de 1835 y que, por un criterio de posterioridad, la norma patria debió ser preferida a la de la Real Cédula. La elección de este criterio no fue accidental, pues la Corte tuvo oportunidad de revisar una causa que giraba en torno a los mismos hechos básicos, y reiteró la primacía de la norma de $1791^{108}$.

Menos debate se agitó respecto de otros puntos relevantes, como el de que, declarado nulo el contrato, no había derecho del fisco a percibir sumas por alcabala. Ello tanto antes de la entrada en vigor del Código Civil ${ }^{109}$, como después de ella ${ }^{110}$, por la razón de que al declararse la invalidez se entiende que ningún contrato ha sido celebrado.

Por el contrario, si un contrato se resolvía por incumplimiento de alguna de las partes $^{111}$, o si se extinguía de mutuo acuerdo entre ellas ${ }^{112}$, la alcabala era debida y el Fisco no era obligado a restituir las sumas pagadas. Y si un contrato estaba sujeto a condición suspensiva para su celebración, y esta no se verificaba, no se debía alcabala ${ }^{113}$.

Por último, debe tenerse presente que existió alguna discusión sobre cómo ciertas operaciones traslaticias de dominio se sujetaban al gravamen de la alcabala.

En cuanto a la permutación, el punto fue rápidamente enfrentado por las autoridades patrias. En 1819, el Administrador General de Aduanas se dirigió al Senado para que este resolviera si, dada una permuta, se debían dos alcabalas o solo una. El Senado siguió al fiscal informante, entendiendo que "por ser dos las enajenaciones, son dos los derechos" 114 . Las cuestiones referidas a alcabalas por permutación no parecen haber sido numerosas, pero ocasionalmente eran revisadas por la jurisprudencia ${ }^{115}$.

También se examinó el caso de la dación en pago. En una especie de 1843, se estimó que la entrega judicial de un inmueble a un acreedor, en pago por una deuda diversa, debía pagar alcabala, apoyándose la Corte Suprema en la ley de 1835 y en normas hispánicas antiguas ${ }^{116}$. En efecto, para evitar que se entendiera que se trataba de una operación exceptuada -al menos de acuerdo al derecho castellano-indiano- del derecho de alcabala, invocó una norma de la Nov. Recop. que disponía que "de todos los trueques que se ficiesen de unas cosas a otras, semejantes y no semejantes, quier intervenga en ello dinero o no, que de

\footnotetext{
108 MARTINEZZ CON FISCO (1865).

109 BRUNNER CON FISCO (1851).

110 VARGAS CON FiSCO (1861), Íñguez CON FisCo (1865). De MALDINI CON FiSCO (1862) se desprende el criterio de que, si bien es necesaria una sentencia judicial para que la nulidad impidiera el cobro de la alcabala, no es necesario que dicha nulidad se declarara explícitamente en la sentencia, sino que bastaba con que operara implícitamente en ella.

111 SÍNDICO DEL CONCURSO dE FARÍAS CON FiSCO (1863).

112 HerRera CON FisCo (1850), Godor CON FisCo (1866). En CHACÓN CON FisCo (1863) se matizaba el punto, por cuanto "consumado el contrato de compraventa, las partes no pueden desistirse para el efecto de solicitar la devolución de la alcabala, sino dentro [de] las veinticuatro horas siguientes a la formación del cargo por ella, según lo dispuesto en el art. 15 del Supremo decreto de 24 de julio de 1847 ”.

113 AVARIA CON FISCO (1848).

114 Senado Conservador, 7 de diciembre de 1819 (SCL, III, p. 410).

115 ARCE CON FISCO (1843), ARCE CON FISCO (1844).

116 Fisco con Soto Aguilar y Puga (1843).
} 
todo se pague el alcabala"117, subsumiendo a la dación en pago dentro de la noción de trueque; y una de las Partidas que entendía que la entrega judicial de un bien debía entenderse que lo era "como en manera de compra" 118 .

Asimismo, suscitó atención el cobro de alcabalas frente a una subasta. Por ejemplo, los tribunales estimaron a su respecto que, si esta se suspendía, también se suspendía el cobro de la alcabala ${ }^{119}$, y que si la sentencia adjudicatoria fijaba un gravamen sobre el bien, ello no era per se un óbice para el cobro del impuesto ${ }^{120}$.

Conviene concluir esta sección evocando que hubo conflictos relacionados con pagos de alcabalas derivados de la enajenación de eventuales inmuebles por adherencia y por destinación.

Respecto de los inmuebles por adherencia, la regla general era que, enajenado el predio que los contenía, aquellos debían pagar alcabala: así se juzgó, por ejemplo, respecto de un molino y la finca respectiva ${ }^{121}$. Pero los tribunales tenían que estar atentos frente a los casos en que la enajenación explícitamente tenía por objeto el edificio, y no el predio: en tales casos no se debía alcabala ${ }^{122}$, como por ejemplo en la venta de un establecimiento de hornos de fundición sin el terreno respectivo ${ }^{123}$.

Por último, en lo concerniente a los inmuebles por destinación, al menos a partir de la aplicación del Código Civil se entendió que debían computarse para el cálculo de la alcabala, porque "estas cosas, como destinadas permanentemente al uso, cultivo y beneficios del fundo, están comprendidas, según lo dispuesto en los arts. 570 y 573 del Código Civil en la categoría de los inmuebles"124.

\subsection{El Pago de la alcabala}

En lo que al pago de la alcabala se refiere, cabe puntualizar tres aspectos principales. Primeramente, el lugar de su pago; en segundo lugar, la determinación del sujeto obligado al pago; y, terceramente, el hecho de que un pago indebido daba derecho a exigir la restitución de lo indebidamente pagado.

La cuestión del lugar en que ella debía pagarse tuvo importancia práctica, principalmente mientras subsistió el régimen de las alcabalas subastadas. Sobre los bienes raíces, el principio fijado por las leyes españolas no presentaba mayores inconvenientes: "el alcabala

\footnotetext{
117 Novísima Recopilación, Libro X, Tít. XII, ley 11.

118 Partida Tercera, Tít. XXVII, ley $6^{\mathrm{a}}$.

119 FISCO CON PAGÉ (1854), FELIÚ CON FISCO (1865).

120 TAGLE CON FISCO (1864).

121 GARCIA HUIDOBRO CON FisCO (1857).

122 Fisco con De SANTIAGo Concha (1864), BlanCo GARCÉs CON FisCo (1864). Este tipo de conflictos siguió suscitando controversias dogmáticas, al punto de que, con posterioridad a este período, en 1873, un decreto supremo del Presidente Errázuriz debió zanjar la controversia declarando que "la transmisión de dominio de los edificios separados del suelo no está gravada con derecho de alcabala, a menos que sea uno mismo el dueño del edificio y del terreno" (BLDG, XLI, $2^{\circ}$ volumen, p. 194).

123 DE LA CERDA CON FISCO (1862).

124 Huidobro Morandé CON Fisco (1863).
} 
de bienes raíces que se vendieren o trocaren, se pague en el lugar donde estuvieren los bienes" 125 .

Pero, por el contrario, respecto de los muebles se agitó más de alguna controversia, dada la complejidad de la norma de la Novísima Recopilación que abordaba el punto ${ }^{126}$. Así, una vista fiscal de principios del período expresaba que el impuesto se debía pagar en el lugar en donde se había perfeccionado la compraventa: "ningún pretexto puede eximir a los vendedores del pago de las alcabalas; y a más de que estos no la pagaron al introducirlos en esta ciudad, es claro que deben hacerlo en el alcabalatorio donde se celebró la venta" ${ }^{27}$. $Y$ en un expediente de 1830 , la judicatura tuvo oportunidad de reafirmar este principio ${ }^{128}$, quedando claro del informe de los Ministros de Aduana que tal era "el lugar donde se verifica la venta y entrega la especie" ${ }^{129}$. De acuerdo al fiscal Francisco Antonio Elizalde, tal era el "uso y costumbre inveterada desde la creación de las alcabalas"130, con lo que se advierte que en materias tributaria y administrativa la costumbre jugaba un rol al menos discreto, como también aparece de otras fuentes ${ }^{131}$.

A partir de la estatización de las alcabalas en 1831, este problema parece haber aminorado su relevancia en las discusiones jurídicas. Ello puede explicarse por el hecho de que, a pesar de que los funcionarios encargados del cobro -las Tesorerías, las Aduanas o el Estanco, dependiendo de la época y las circunstancias- divergían en sus respectivas esferas territoriales, todos actuaban en interés de un mismo patrimonio, el Fisco ${ }^{132}$.

Por otra parte, en lo concerniente a qué sujeto estaba obligado a pagar el tributo, la regla general procedente del derecho castellano-indiano disponía que lo fuera el vendedor ${ }^{133}$, salvo las excepciones previstas por la ley ${ }^{134}$, entre las que cabía contar el caso del vendedor ausente ${ }^{135}$. El Código Civil incorporó grosso modo este criterio, disponiendo que "los impuestos fiscales o municipales, las costas de la escritura y de cualesquiera otras solemnidades de la venta, serán de cargo del vendedor; a menos de pactarse otra cosa"136.

En fin, debe subrayarse el hecho de que un sujeto que pagase alcabalas fuera de los casos y montos establecidos por la ley tenía derecho a la restitución de lo indebidamente

\footnotetext{
125 Novísima Recopilación, Libro X, Tít. XII, ley 13.

126 Novísima Recopilación, Libro X, Tít. XII, ley 12.

127 Vista fiscal de 17 de octubre de 1821 (f. 43) en el expediente CAMPOS CON HACENDADOS DEL PARTIDO DE RANCAGUA (1822).

128 GOBERNADOR DE RANCAGUA (1830).

129 Informe de los Ministros de Aduana, de 27 de octubre de 1830 (f. 32 vta.) en el expediente GOBERNADOR DE RANCAGUA (1830).

130 Vista fiscal de 3 de noviembre de 1830 (f. 35 vta.) en el expediente GOBERNADOR DE RANCAGUA (1830).

131 Bocksang Hola (2015), pp. 83-87.

132 Pero la existencia de un decreto supremo de 1877, emitido por el Presidente Pinto y estableciendo específicamente en qué administración del Estanco debía pagarse el tributo muestra que los roces derivados de estas eventuales incompetencias no desaparecieron del todo luego de la estatización de las alcabalas (BLDG, XLV, p. 451).

133 Novísima Recopilación, Libro X, Tít. XII, ley 11.

134 Novísima Recopilación, Libro X, Tít. XII, ley 18.

135 FISCO CON RAMOS (1863).

136 Código Civil, artículo 1806.
} 
pagado $^{137}$. Por consiguiente, no existía un derecho automáticamente adquirido de los subastadores o del Fisco sobre dichas sumas. Así, por ejemplo, si el contribuyente declaraba un valor erróneo del bien sobre el cual debía calcularse el monto del tributo, tenía derecho a la devolución del exceso ${ }^{138}$; y si enajenaba una cuota del bien, solo debía pagar alcabala por la cuota respectiva ${ }^{139}$. Asimismo, si se declaraba un valor del inmueble sin deducir las respectivas amortizaciones ${ }^{140}$ o dividendos ${ }^{141}$ que lo afectaban, o sin descontar una cantidad acensuada sobre la finca ${ }^{142}$, o una capellanía ${ }^{143}$, también se tenía derecho a restitución. En ocasiones, aun frente a una fundamentación insatisfactoriamente desarrollada por juez de letras sobre el punto, la Corte Suprema hacía caso omiso de ella y derechamente ordenaba devolver las correspondientes sumas, sin ofrecer consideraciones en su reemplazo ${ }^{144}$. Y, en cuanto a intereses, de una sentencia implícitamente aparece que, de haber estado el Fisco de mala fe, la restitución de la suma indebidamente pagada hubiera debido comprender$\operatorname{los}^{145}$.

\subsection{El COBRo de la alCABAla}

Este rubro no parece haber sumado muchas controversias en el período examinado; pero, en cuanto a la prescripción de la acción de cobro, sí ejemplifica el rol que jugó el Código Civil en la modelación del derecho tributario chileno.

El caso más patente aparece de una sentencia de 1863, que permite graficar con bastante nitidez la situación previa a la entrada en vigor del Código Civil de las acciones dirigidas al cobro de la alcabala. Examinando obligaciones devengadas con anterioridad a dicho cuerpo normativo, esta sentencia da cuenta de que "no prescriben las alcabalas ni aun por tiempo inmemorial" "146, basándose esencialmente en tres normas del libro XI, título VII de la Novísima Recopilación que conviene explicar.

La primera de ellas se refiere al "tiempo necesario para prescribir el señorío de los pueblos", indicando que "la posesión inmemorial, probándose según y como y con las calidades que la ley de Toro requiere... basta para adquirir contra Nos [la Corona] y nuestros sucesores qualesquier ciudades, villas y lugares, y Jurisdicciones civiles y criminales, y qua-

137 Entre otros, véase AVARIA CON FISCO (1848), NÚNEEZ CON FISCO (1848), BRUNNER CON FISCO (1851), SCHWArumberg con Fisco (1861), Padilla con Fisco (1862), Blanco Garcés con Fisco (1864), Hermida CON Fisco (1866).

138 EBNER CON FISCO (1864).

139 MARDONES CON FISCO (1844), URMENETA Y COMPARTES CON FISCO (1866).

140 DIAZ CON FISCO (1865).

141 Álamos con Fisco (1865).

142 Soffia CON FiSCO (1865). Pero en PUENTE CON FISCO (1865) se fija el criterio complementario de que "para eximirse del pago de alcabala en las trasmisiones del dominio de un fundo relativamente a los capitales acensuados que los graven, es indispensable acreditar que al tiempo de su fundación se pagó la respectiva alcabala o que no existía este impuesto".

143 Állvarez con Fisco (1865).

144 MONVOISIN CON FISCO (1854).

145 DÍAZ CON FISCO (1865): "se declara: que el fisco debe devolver al demandante la parte de alcabala correspondiente a la suma amortizada, sin intereses porque el fisco no la recibió de mala fe".

146 FISCO CON RAMOS (1863). 
lesquiera cosa y parte dello", pero declarando que "asimismo lo que las leyes dicen, que las cosas del Reyno no se pueden ganar por tiempo, se entienda de los pechos y tributos a Nos debidos" ${ }^{147}$. En otras palabras, debiéndose un tributo al Rey -rol que en el caso de Chile pasó a ser asumido por el Estado-, no podía oponerse una prescripción.

Una segunda ley ya se refiere explícitamente a las alcabalas, señalando que los recaudadores no podrían cobrar las sumas adeudadas por ellas "cuatro años después de pasado el dicho año de su recaudamiento", salvo el caso de que la prescripción se hubiera interrumpido por actos realizados por el recaudador. Sin embargo, la norma concluye con lo más relevante: "esto se entienda en lo que fuere debido a los dichos nuestros recaudadores y arrendadores, y no aquello que queda por recaudar para Nos por remisión o negligencia de los dichos nuestros recaudadores y arrendadores" ${ }^{148}$. En términos prácticos, dentro de la óptica republicana, debiese entenderse que esta norma habilitaba al Fisco para cobrar en cualquier momento las deudas por alcabalas, sin sujeción a prescripción alguna, si los funcionarios públicos correspondientes hubieran sido negligentes en exigir su cumplimiento.

Y también apuntaba directamente a las alcabalas la tercera ley expresada en la sentencia, focalizándose en el hecho de que las alcabalas eran una prerrogativa real, no adquirible por ninguna otra persona. "Mandamos que agora ni en ningún tiempo, por haber cogido y llevado las personas suso dichas, y sus herederos y sucesores, las dichas alcabalas o parte de ellas, en las dichas sus ciudades, villas y lugares, o en otros qualesquier destos mis reynos, y de hecho las quisiesen llevar y llevasen adelante por qualquier tiempo, aunque fuese inmemorial, pública o secretamente, aunque en ello paresciere tolerancia nuestra o de nuestros sucesores, que por ello no puedan adquirir ni adquieran posesión, título ni derecho, ni puedan alegar uso ni costumbre alguna, ni prescripción, aunque sea inmemorial" ${ }^{149}$.

De las tres normas transcritas desprendió la Corte Suprema un régimen de imprescriptibilidad $^{150}$ : nadie puede prescribir adquisitivamente un tributo debido (ley $4^{a}$ ), nadie puede prescribir adquisitivamente la prerrogativa para cobrarlos (ley 9a), y no hay prescripción extintiva oponible al Rey -o el Estado- frente a la negligencia de los recaudadores de alcabalas (ley $8^{\mathrm{a}}$ ).

Como ya se ha expresado, es llamativo el hecho de no haberse aludido al Código Civil para resolver la contienda, lo que se explica por tratarse de un hecho imponible anterior a 1857. Pero hay otro aspecto que debe tenerse en cuenta, y aparece de un análisis transversal de las sentencias que corrieron entre 1857 y 1866: ninguna otra parece haberse referido al problema de la prescripción. La razón probablemente es doble. Por una parte, de tratarse de una operación realizada antes de 1857 , se le hubiera aplicado el criterio castellano-indiano de imprescriptibilidad ${ }^{151}$. Por otra, de tratarse de una operación realizada a partir de la entrada en vigor del Código, el plazo de prescripción más corto eventualmente susceptible

\footnotetext{
147 Novísima Recopilación, Libro X, Tít. IX, ley $4^{\mathrm{a}}$.

148 Novísima Recopilación, Libro X, Tít. IX, ley $8^{\mathrm{a}}$.

149 Novísima Recopilación, Libro X, Tít. IX, ley 9a.

150 También lo subraya EsCRICHE (1891) p. 122.

151 En el mejor de los casos, de acuerdo al criterio del artículo 25 de la ley de 7 de octubre de 1861 (BLDG, XXIX, p. 366), si el prescribiente hubiera elegido una norma de prescripción más favorable y más reciente, "la prescripción no empezará a contarse sino desde la fecha en que aquella [la nueva ley] hubiese empezado a re-
} 
de ser invocado -a falta de otra norma especial- no hubiera vencido aún: el de la regla del Código Civil que disponía que tal lapso "es en general de diez años para las acciones ejecutivas y de veinte para las ordinarias"152.

\section{CONCLUSIÓN}

1. Por lo general meramente reconocida como institución tributaria del derecho castellano-indiano, la alcabala se integró al régimen patrio y suscitó interesantes debates en el derecho chileno durante los dos primeros tercios del siglo XIX.

2. En lo político, no resultó sencillo acomodar a este impuesto en la institucionalidad patria, pero se logró transmutarla con una lógica modernizada y simplificada, dotada de un nuevo marco operativo (sección 1).

3. En lo jurídico, su aplicación dio lugar a interesantes controversias prácticas, entre las cuales pueden destacarse ciertas perturbaciones dogmáticas suscitadas por la entrada en vigor del Código Civil, así como cuestiones que permitieron reafirmar el principio de legalidad tributaria y la proscripción del enriquecimiento injusto (sección 2).

4. Así, el período que corrió entre 1810 y 1866 puede calificarse como una etapa de reconfiguración y consolidación de la alcabala en el derecho chileno, durante la cual se permitió el desarrollo de soluciones justas a través de una sana conjunción de influencias castellano-indianas y patrias. Aunque la importancia económica de las alcabalas decayó en comparación al rol protagónico que habían jugado durante el Reino de Chile, el estudio político-jurídico de su tratamiento durante el período histórico que es objeto de este trabajo permite arrojar nuevas perspectivas sobre la evolución de los derechos administrativo, civil y tributario en Chile, y sobre su recíproca interacción en la construcción de nuestro régimen jurídico.

\section{BIBLIOGRAFÍA CITADA}

Araya Bugueño, Manuel (2003): "Fiscalidad y Economía Regional: Arica 1759-1799", Chungará, Revista de Antropología Chilena, vol. 35, No 1: pp. 141-157.

Avilés Hernández, Víctor Manuel (2005): Legalidad tributaria (Santiago, Editorial Jurídica de Chile).

Barros Arana, Diego (2000-2005): Historia General de Chile (Santiago, Editorial Universitaria).

Bocksang Hola, Gabriel (2015): El nacimiento del derecho administrativo patrio de Chile (1810-1860) (Santiago, Thomson Reuters).

Bravo Lira, Bernardino (1986): Historia de las instituciones políticas de Chile e Hispanoamérica (Santiago, Editorial Jurídica de Chile).

gir”. Esta norma hubiera podido ser la del Código Civil que se cita a continuación, y que a la sazón no hubiera producido la prescripción por la misma razón que allí, al citarla, se expresa.

152 Código Civil, artículo 2515. También hubiera podido tomarse en cuenta el artículo 2517: "toda acción por la cual se reclama un derecho se extingue por la prescripción adquisitiva del mismo derecho”. 
Campos Harriet, Fernando (1992): Historia constitucional de Chile (Santiago, Editorial Jurídica de Chile).

Carmagnani, Marcello (1961): "La oposición a los tributos en la segunda mitad del siglo XVIII", Revista Chilena de Historia y Geografía, N 129, pp. 158-195.

Carvallo Herrera, Sergio (1961): Legislación tributaria chilena (Santiago, Editorial Universitaria).

Cattaneo Escobar, Isaías Daniel (2013): Los impuestos fiscales a las rentas agricolas en el siglo XIX. Memoria para optar al grado de licenciado en Ciencias Jurídicas y Sociales, Universidad de Chile.

Celaya NÁndez, Yovana (2008): "La cesión de un derecho de la Real Hacienda: la administración del impuesto de la alcabala novohispana en el siglo XVII. Tres estudios de caso", América latina en la historia económica $\mathrm{N}^{\circ}$ 33, pp. 93-125.

Choque Mariño, Carlos; Díaz Araya, Alberto (2016): "El detrimento de la Real Hacienda, irregularidades en su funcionamiento y administración. La visita a la Caxa Real de Arica en 1653", Diálogo Andino No 49, pp. 443-457.

DíAZ, José; LÜDERs, Rolf; WaGner, Gert (2016): Chile 1810-2010. La República en cifras (Santiago, Ediciones Universidad Católica de Chile).

Durán Rojo, Luis Alberto, y Mejía Acosta, Marco (2014): "El impuesto de alcabala en el Perú", Derecho y Sociedad N 43, pp. 345-365.

EsCrICHE, Joaquín (1891): Diccionario Razonado de Legislación y Jurisprudencia (París, Librería de Garnier Hermanos).

Evans de la Cuadra, Enrique; Evans Espiñeira, Eugenio (1997): Los tributos ante la Constitución (Santiago, Editorial Jurídica de Chile).

Fonseca, Fabián de; Urrutia, Carlos de (1845-1853): Historia general de Real Hacienda (México, Imprenta de Vicente García Torres).

HeIse GonZÁlez, Julio (1959): Historia constitucional de Chile (Santiago, Editorial Jurídica de Chile).

Huneeus Zegers, Jorge (1879-1880): La Constitución ante el Congreso (Santiago, Imprenta de los Tiempos).

Jofré, José; LÜDers, Rolf; Wagner, Gert (2000): Economía chilena 1810-1995. Cuentas fiscales. Documento de trabajo $\mathrm{N}^{\circ} 188$, Instituto de Economía, Pontificia Universidad Católica de Chile.

López Taverne, Elvira (2014) : El proceso de construcción estatal en Chile. Hacienda pública y burocracia (1817-1860) (Santiago, Ediciones de la Dirección de Bibliotecas, Archivos y Museos).

Manuschevich Krasmer, Isaac (1925): Historia de los impuestos fiscales en Chile (Santiago, Imprenta y Encuadernación La Economía).

Montanos Ferrín, Emma; Sánchez-Arcilla, José (1991): Historia del derecho y de las instituciones. Tomo II (Madrid, Dykinson).

Ots y Capdequí, José María (1969): Historia del derecho español en América y del derecho indiano (Madrid, Aguilar).

PASTOR, Rodolfo (1977): "La alcabala como fuente para la historia económica y social de la Nueva España”, Historia Mexicana, vol. 27, Nº 1: pp. 1-16. 
Prado Bustamante, Santiago (1859): Principios elementales de derecho administrativo chileno (Santiago, Imprenta Nacional).

Sagredo Baeza, Rafael (1997): "Chile: 1823-1831. El desafío de la administración y organización de la hacienda pública”, Historia, vol. 30: pp. 287-312.

Salas Aguilar, Mitzi Andrea (2004): Historia del derecho tributario chileno durante el siglo XIX: compilación y estudio (Tesis para optar al grado de licenciado en Ciencias Jurídicas y Sociales, Universidad Central de Chile).

Silva Vargas, Fernando (1972): "El motín de las alcabalas en 1776”, Boletín de la Academia Chilena de Historia, No 86: pp. 22-37.

Solórzano y Pereyra, Juan de (1972): Política indiana (Madrid, Compañía IberoAmericana de Publicaciones).

Villalobos Rivera, Sergio (1958): "El descontento contra la política económica de los Borbones en Chile", Estudios Americanos, No 78-79: pp. 135-143.

\section{NORMAS CITADAS}

Las Siete Partidas (ca. 1265).

Recopilación de Leyes de los Reinos de las Indias (1680).

Novísima Recopilación de las Leyes de España (1805).

Constitución Provisoria para el Estado de Chile (1818).

InSTRUCCIÓN SOBRE DERECHOS DE ALCABALAS, DE 11 DE DICIEMBRE DE 1819 (SCL, III, p. 415; BLDG, 1819-1820, p. 185).

Adición a la Instrucción sobre derechos de alcabalas, de 16 de diciembre de 1819 (SCL, III, P. 434; BLDG, 1819-1820, p. 187).

Declaración del Senado Conservador, de 28 de enero de 1820 (SCl, III, p. 537).

Declaración del Senado Conservador, de 9 de abril de 1820 (SCL, IV, p. 82).

ACta de Unión de 1823 (BLDG, I, P. 21; SCL, VII, p. 33).

Decreto supremo de 2 de MARZO de 1825 (BLDG, II, p. 95).

LEY de 20 de AGOSTO de 1826 (SCL, XII, p. 436).

Ley de 18 de octubre de 1831 (BLDG, V, p. 174).

Decreto Supremo de 15 de junio de 1832 (BLDG, V, p. 177).

Decreto Supremo de 26 de octubre de 1832 (BLDG, V, p. 269).

Constitución Política de la República Chilena (1833).

Decreto Supremo de 26 de junio de 1833 (BLDG, VI, p. 64).

LEY de 17 de MARZO de 1835 (BLDG, VI, p. 193).

LeY de 22 de octubre de 1835 (BLDG, VI, p. 214).

Decreto Supremo de 10 de noviembre de 1842 (BLDG, X, p. 345).

LeY de 19 DE DiCIEMBRE DE 1842 (BLDG, X, p. 400).

Decreto supremo de 10 de noviembre de 1843 (BLDG, XI, p. 197).

Decreto supremo de 29 de marzo de 1851 (BLDG, XIX, p. 177).

Código Civil Chileno (1857).

LEY de 31 DE JULIO dE 1860 (BLDG, XXVIII, p. 189).

LeY de 7 de octubre de 1861 (BLDG, XXIX, p. 366). 
Decreto Supremo de 3 de septiembre de 1873 (BLDG, XLI, 2º volumen, p. 194).

Decreto Supremo de 31 de agosto de 1877 (BLDG, XLV, p. 451).

\section{JURISPRUDENCIA CITADA}

Real Hacienda CON fiadores de Mata Pinilla (1817): Subdelegado de Puchacay, 21 de febrero de 1817, Archivo Judicial de Puchacay, volumen 3, pieza 21, f. 9 vta.

Hospital de MUJERES CON SUBASTADOR DE ALCABALAS (1819): Gobernador Intendente de Santiago, 7 de septiembre de 1819, Archivo Judicial de Santiago, volumen 499, pieza 8, f. 23.

GARIN CON FISCO (1820): Gobernador Intendente de Santiago, 27 de noviembre de 1820, SCL, IV, p. 523.

Campos con Hacendados del Partido de Rancagua (1822): Junta Superior de Hacienda, 15 de julio de 1822, Archivo de la Real Audiencia, volumen 2185, pieza 3, f. 55.

GARÍN CON FISCO (1822): Junta Superior de Hacienda, 9 de agosto de 1822, Archivo Judicial de Santiago, volumen 1242, pieza 12, f. 7 vta.

FISCO CON OLAVE (1823): Junta Superior de Hacienda, 3 de julio de 1823, Archivo Judicial de Talca, volumen 101, pieza 10, f. 43.

Pérez de VAlenzuela con Municipalidad de San Fernando (1826): Corte de Apelaciones, 31 de mayo de 1826, Archivo de la Real Audiencia, volumen 2402, pieza 5 (primera parte), f. 17.

EXPEDIENTE SOBRE ALCABALA DE ESPEJOS (1827): Corte de Apelaciones, 22 de junio de 1827, Fondo Varios, volumen 295, f. 67.

BARRIL CON FISCO (1828): Corte de Apelaciones, 28 de junio de 1828, Fondo Varios, volumen 295, f. 120 vta.

FISCO CON ÁVILA (1830): Corte de Apelaciones, 26 de febrero de 1830, Archivo Judicial de Santiago, volumen 643, pieza 2, f. 51 vta.

GOBERNADOR DE RANCAGUA (1830): Juzgado de Letras de Santiago, 16 de diciembre de 1830, Archivo Judicial de Santiago, volumen 1245, pieza 12, f. 52 vta.

Contra de la PeÑa Y otros (1832): Corte Suprema, 17 de julio de 1832, El Araucano n ${ }^{\circ}$ 99, 3 de agosto de 1832, p. 3.

Soto CON FISCO (1833): Corte de Apelaciones, 27 de noviembre de 1833, SCL, XXVII, p. 257.

SOSA CON FISCO (1842): Corte Suprema, $1^{\circ}$ de marzo de 1842, GT No 15 [1842], p. 55.

Fisco CON Soto Aguilar y PUGa (1843): Corte Suprema, 16 de junio de 1843, GT no 76 [1843], p. 2.

ARCE CON FISCO (1843): Corte Suprema, 28 de julio de 1843, GT No 82 [1843], p. 1.

ARCE CON FISCO (1844): Corte Suprema, 28 de mayo de 1844, GT No 121 [1844], p. 3.

MARDONES CON FISCO (1844): Corte Suprema, 3 de noviembre de 1844, GT No 148 [1844], p. 1.

CAllejas con Fisco (1846): Corte Suprema, 21 de julio de 1846, GT No 228 [1846], p. 770. 
AVARIA CON FISCO (1848): Corte Suprema, 4 de julio de 1848, GT no 321 [1848], p. 1826. NÚNEEZ CON FISCO (1848): Corte Suprema, 25 de julio de 1848, GT No 324 [1848], p. 1858.

HERRERA CON FISCO (1850): Corte Suprema, 26 de abril de 1850, GT No 408 [1850], p. 2672.

BRUNNER CON FISCO (1851): Corte Suprema, 7 de noviembre de 1851, GT No 485 [1851], p. 3525 .

MonVIISIN CON FISCO (1854): Corte Suprema, 17 de noviembre de 1854, GT No 641 [1854], p. 5500.

FISCO CON PAGÉ (1854): Corte Suprema, 21 de noviembre de 1854, GT No 642 [1854], p. 5513.

GARCÍA HUIDOBRO CON FISCO (1857): Corte Suprema, 17 de noviembre de 1857, GT No 803 [1857], p. 7945.

SCHWARUMBERG CON FISCO (1861): Corte Suprema, 2 de abril de 1861, GT No 979 [1861], p. 350.

VARGAS CON FISCO (1861): Corte Suprema, 21 de mayo de 1861, GT No 986 [1861], p. 516.

MALDINI CON FISCO (1862): Corte Suprema, 10 de enero de 1862, GT No 1019 [1862], p. 50.

DE LA CERDA CON FISCO (1862): Corte Suprema, 10 de enero de 1862, GT No 1019 [1862], p. 52.

PAdILLA CON FISCO (1862): Corte Suprema, 7 de marzo de 1862, GT No 1027 [1862], p. 203.

Síndico del concurso de FARÍAs con Fisco (1863): Corte Suprema, 21 de abril de 1863, GT No1086 [1863], p. 259.

FisCo CON RAmos (1863): Corte Suprema, 4 de agosto de 1863, GT No 1101 [1863], p. 587.

HuIDOBRo MoRANDÉ CON FISCO (1863): Corte Suprema, 22 de septiembre de 1863, GT n ${ }^{\circ}$ 1108 [1863], p. 725.

CHACÓN CON FISCO (1863): Corte Suprema, 20 de octubre de 1863, GT No 1112 [1863], p. 795.

EBNER CON FISCO (1864): Corte Suprema, 23 de agosto de 1864, GT No 1156 [1864], p. 571.

Fisco con De SANTiago Concha (1864): Corte Suprema, 25 de octubre de 1864 (GT No 1165 [1864], p. 785)

HeATLEY EVANS Y CA. CON FISCO (1864): Corte Suprema, 9 de noviembre de 1864, GT No 1167 [1864], p. 826.

BLANCO GARCÉS CON FISCO (1864): Corte Suprema, 29 de noviembre de 1864, GT No 1170 [1864], p. 890.

TAGLE CON FISCO (1864): Corte Suprema, 27 de diciembre de 1864, GT No 1174 [1865], p. 3. DÍAZ CON FISCO (1865): Corte Suprema, 4 de abril de 1865, GT No 1188 [1865], p. 257.

SOFFIA CON FISCO (1865): Corte Suprema, 23 de mayo de 1865, GT No 1195 [1865], p. 395. 
Álamos CON Fisco (1865): Corte Suprema, 23 de junio de 1865, GT No 1199 [1865], p. 486.

Álvarez COn Fisco (1865): Corte Suprema, 16 de agosto de 1865, GT No 1207 [1865], p. 659.

ÍñgueZ CON Fisco (1865): Corte Suprema, 18 de agosto de 1865, GT No 1207 [1865], p. 659.

Puente CON FISCO (1865): Corte Suprema, 3 de octubre de 1865, GT No 1214 [1865], p. 787.

OSSA CON FISCO (1865): Corte Suprema, 24 de octubre de 1865, GT No 1217 [1865], p. 841.

GONZALEZ CON FISCO (1865): Corte Suprema, 31 de octubre de 1865, GT No 1218 [1865], p. 867.

MARTÍNEZ CON FISCO (1865): Corte Suprema, 14 de noviembre de 1865, GT No 1220 [1865], p. 914.

OCAMPO CON FISCO (1865): Corte Suprema, 12 de diciembre de 1865, GT No 1224 [1865], p. 1010.

FELIÚ CON FISCO (1865): Corte Suprema, 12 de diciembre de 1865, GT No 1224 [1865], p. 1010.

MERINO CON FISCO (1866): Corte Suprema, 10 de abril de 1866, GT No 1240 [1866], p. 212.

GODOY CON FISCO (1866): Corte Suprema, 20 de abril de 1866, GT No 1242 [1866], p. 245.

URMENETA Y COMPARTES CON FISCO (1866): Corte Suprema, 3 de agosto de 1866, GT n ${ }^{\circ}$ 1257 [1866], p. 533.

LIRA CON FISCO (1866): Corte Suprema, 21 de noviembre de 1866, GT No 1273 [1866], p. 808.

HERMIDA CON FISCO (1866): Corte Suprema, 11 de diciembre de 1866, GT No 1276 [1866], p. 855. 
